\title{
Roughness Evaluation USing Abbott-Firestone Curve Parameters
}

\author{
Dana Kubátová, Martin Melichar
}
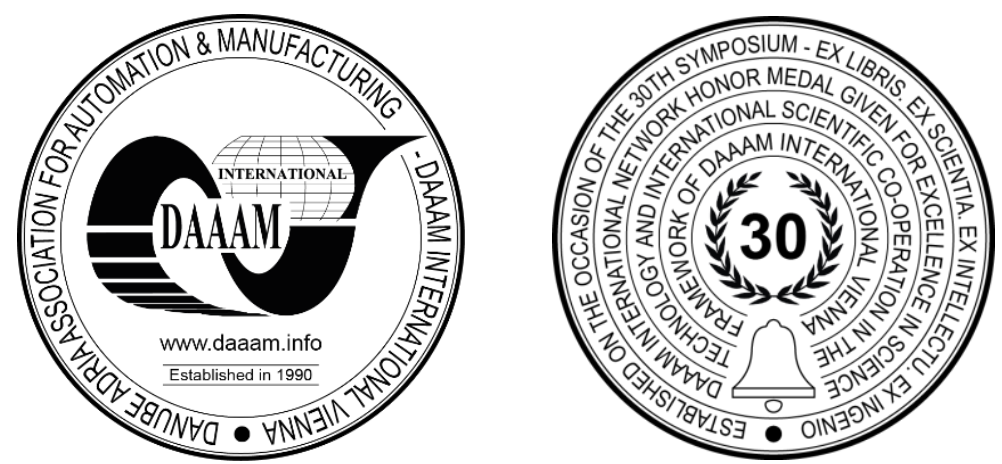

This Publication has to be referred as: Kubatova, D[ana] \& Melichar, M[artin] (2019). Roughness Evaluation Using Abbott-Firestone Curve Parameters, Proceedings of the 30th DAAAM International Symposium, pp.0467-0475, B. Katalinic (Ed.), Published by DAAAM International, ISBN 978-3-902734-22-8, ISSN 1726-9679, Vienna, Austria DOI: $10.2507 / 30$ th.daaam.proceedings.063

\begin{abstract}
Article deals with a highly current topic of evaluation of critical surface integrity parameters. The surface integrity to be the relationship between the required functional properties of the surface and the change in the properties of the new surface. Surface can be evaluated using two basic properties, namely the spatial arrangement of the surface (surface roughness) and the physico-chemical properties of the surface layer.

Article is focused on the first area of evaluation - surface roughness assessment. The main task of this article is to verify the assumption that the parameters Abbot curve are independent of the type of software filter used. Parameters of Abbot curve come to the forefront using in industrial practice in last 5 years. This is mainly due to the assumption of independence from the type of software filter used in their evaluation. This was proved by the test. Abbot curve is influenced just type of used etalon. Abbot curve is not influenced type of software filter.
\end{abstract}

Keywords: Roughness; software filters; Abbott-Firestone curve; statistical analysis.

\section{Introduction}

Measurement and evaluation of surface roughness has seen significant qualitative advances in recent years. Leading manufacturers of measuring instruments (Hommel, Carl Zeiss and others) have actively responded to new demands. This is mainly due to the fact that the surface structure is often checked with dedicated measuring instruments. For this reason, the manufacturers of these machines are also the main drivers for developing standards related to high quality evaluation of machined surfaces. [2]

This has ultimately led to improvements in the existing surface measurement and evaluation technologies, as well as improved methods, measurement and surface evaluation systems that are still under development. [6], [7] The surface structure evaluation system is defined by a set of standards that describe the marking, measurement and evaluation of surface texture, calibration of measuring instruments and other aspects. These are GPS (Geometrical Product Specification) standards. [5] 
In general, measurement and evaluation of surface texture is a separate area of metrology, where special technology can be used to characterize the surface quality.

Under the term 'surface quality' it is possible to imagine a set of properties of the investigated surface of an object. These are classified based on the spatial arrangement of the surface - roughness (texture, morphology), and then physical and chemical properties. The quality of the surface depends on some very important characteristics such as: efficiency, reliability, performance (functional properties?), appearance, and last but not least, the cost of the entire production process. When machining a surface, we can influence the choice of work piece material, the right cutting tool, the selection of suitable cutting conditions, and the coolant. [15] For dynamically stressed components, we investigate the fatigue factors, the properties of the selected material and investigate the fatigue fractures that occur on the surface of the component or just below it. With static stress, we are most often confronted with cases of compressive, tensile, bending and torsional stresses, where the greatest stresses occur on the surface of the part. Corrosion resistance under functional stress must be taken into account in terms of surface micro geometry and the consequent risk of fatigue fracture. All this is currently 'hiding' and evaluated under the term 'surface integrity'.

Therefore, we consider the integrity of the surface to be the relationship between the required functional properties of the surface and the change in the properties of the new surface that have been produced by a certain technological process. This is caused by the relationship between micro-irregularities (geometric properties) and physical properties (stress and hardness).

Surface integrity can be evaluated by two basic properties, namely the spatial arrangement of the surface (surface roughness) and the physical and chemical properties of the surface layer. [1], [3] Surface roughness is used not only in engineering companies, but also in construction, in transport for the solution of roughness of road surfaces, when working with wood, and last but not least also in military technology.

The correct way to monitor and evaluate the micro geometry of a surface layer is a fundamental factor in ensuring the durability, strength, reliability and efficiency of machine parts. Due to functional surface requirements, many surface roughness parameters have been introduced to provide a trustworthy description, although most possible parameters in surface roughness evaluation are neglected in current technical practice. As a result of the development of a more accurate description, the height characteristics $(\mathrm{Ra}, \mathrm{Rz}, \ldots)$ were supplemented with shape characteristics $(\mathrm{Rmr}, \mathrm{Rdc}, .$.$) and$ subsequently with shape parameters that determine the share of the bearing load $(\mathrm{Rk}, \mathrm{Rvk}, \ldots)$. In this paper, we will focus on the shape parameters defining the bearing load share, i.e. the parameters of the Abbott-Firestone curve. These are described in ISO 13565-2:1998, which was based on the German standard DIN 4777: 19990, which was the first to introduce the function parameters using a graphic construction of the bearing load curve. [4], [8]

The Abbott-Firestone curve is used to evaluate the parameters Rk, Rpk, Rvk, Rmr1, Rmr2, which are obtained from the filtered surface and are usually evaluated based on a graphic representation, see Figures $1 \mathrm{a}-\mathrm{b}$.

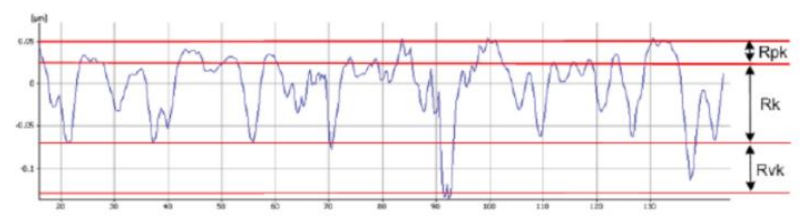

Fig. 1a. Roughness profile

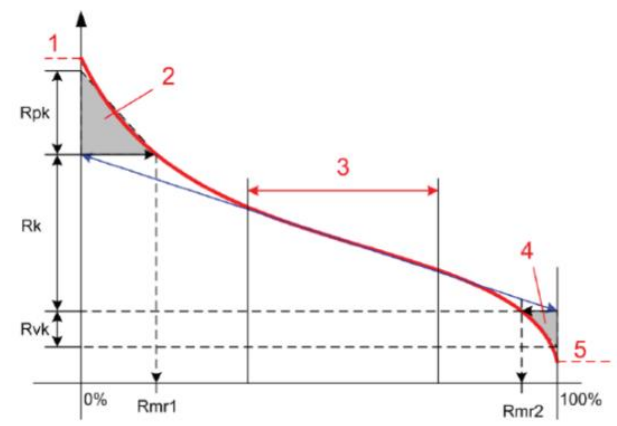

Fig. 1b. Abbott-Firestone curve 
Description of figures $1 \mathrm{a}$ and $1 \mathrm{~b}$ :

1 - defines the maximum height of the measured profile; 2 - shows the field with reduced peak height; 3 - the area with minimum slope; 4 - shows the field with reduced groove depth; 5 - defines the minimum depth of the measured profile.

The X-axis in Figure $1 \mathrm{~b}$ shows the material proportions that represent the percentage of material above the core profile (Rmr1) and the material below the roughness profile (Rmr2).

As described in Article 1 (Post processing of roughness raw data - Barcelona) in practice, we can select the type of evaluation, i.e. software filter, when measuring the surface roughness. The effect of the selected software filter on the Abbott-Firestone curve parameter values was tested in this experiment.

The use of the Abbott-Firestone curve parameters is greatly increasing in industry. [10] These parameters are mainly used when it is necessary to tell from the state of the measured area how the surface will behave, for example when measuring the grinding of engine cylinders.

\section{Description of the experiment}

The test was carried out as part of research conducted in the metrology laboratory of the Regional Institute of Technology at the University of West Bohemia in Pilsen. The laboratory's equipment includes a high-precision profilometer from Hommel Etamic T8000 (Fig. 2).

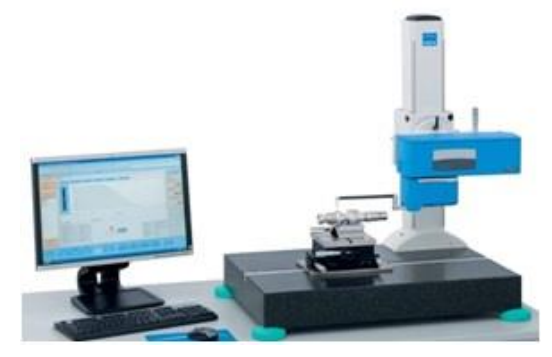

Fig. 2. Hommel Etamic T 8000

The testing included the influence of the selected software filter on the parameters of the Abbot-Firster curve when using different surface roughness values and di. [11] For a detailed description of individual filters see article 14. The changes in surface roughness values were made using surface roughness standards with nominal values of RA0.5; RA1; RA3,2; RA6,3. All standards have a periodic surface structure.

A testing plan was designed using the DOE (design of experiment) methodology. Initially, the measurement included 2 repetitions with randomization of the measurement order. [9] Following the measurement, the experiment was evaluated using the statistical program minitab and the results were analysed.

To evaluate the test, the first step was to investigate the effect of the standard, the filter and their combination using a Pareto graph. [16] Subsequently, the model was compiled and, on the basis of the R-sq value in the model summary, it was decided to make further adjustments or repetitions of the test.

\subsection{An example of the performed analysis can be seen in the parameter $R v k$}

In the initial analysis using the Pareto graph, none of the evaluated parameters of Rvk are significant. This can be seen in Figure 3, where none of the parameters tested exceed the limit value of 2.086. This indicates that none of the influences tested on the Rvk parameter have any significance.

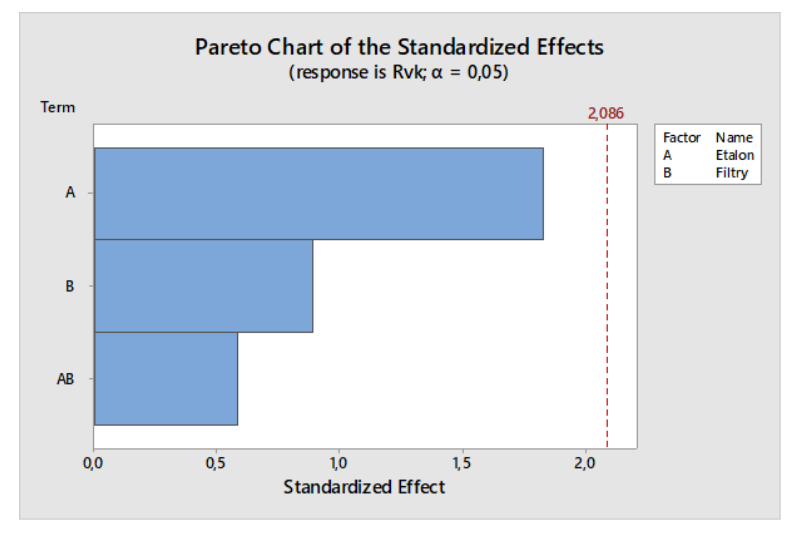

Fig. 3. Pareto graph for parameters Rvk 
In the next step the model was built using the ANOVA methodology. In this it is possible to see a confirmation that, even according to this methodology, no tested parameter is significant for us at this moment (see Table 1 - $\mathrm{P}$ values higher than 0.05).

The only place we approach possible significance is with the Standard parameter, where we approach the limit values in both the Pareto chart and ANOVA.

\begin{tabular}{|l|r|r|r|r|r|}
\hline Source & DF & Adj SS & Adj MS & F-Value & P-Value \\
\hline Model & 19 & 6.896 & 0.3629 & 1.21 & 0.339 \\
\hline Linear & 7 & 3.657 & 0.5224 & 1.74 & 0.157 \\
\hline Standard & 3 & 2.330 & 0.7768 & 2.59 & 0.082 \\
\hline Filters & 4 & 1.327 & 0.3317 & 1.10 & 0.382 \\
\hline 2-Way Interactions & 12 & 3.239 & 0.2699 & 0.90 & 0.564 \\
\hline Standard*Filters & 12 & 3.239 & 0.2699 & 0.90 & 0.564 \\
\hline Error & 20 & 6.010 & 0.3005 & & \\
\hline Total & 39 & 12.905 & & & \\
\hline
\end{tabular}

Table. 1. Analysis of Variance

Subsequently, a model was created for the given parameters of the Abbot-Firestone curve, although none of the tested parameters were found to be significant in the initial analysis.

Rvk = $0.2555-0.1305$ Standard_0.5 + 0.0265 Standard_1 - 0.1784 Standard_3.2 + 0.2823 Standard_6.3

\begin{tabular}{|c|c|r|r|}
\hline S & R-sq & R-sq(adj) & R-sq(pred) \\
\hline 0.548158 & $53.43 \%$ & $9.20 \%$ & $0.00 \%$ \\
\hline
\end{tabular}

Table. 2. Model summary

However, the model has an accuracy of 53\% (see Table 2 of the R-sq values), which is insufficient.

Further tests were necessary. The first test performed was to test the strength of the test. This is a test that shows us the level of test reliability, which means rejecting a first order error and also rejecting a second order error. The strength of the test is a number between 0 and 1, which indicates the probability that the null hypothesis is invalidated, i.e. the probability of finding the null hypothesis invalid. The higher the strength of the test, the better. [12]; [13]

Looking at the test strength test in our case for the Rvk parameter, it can be seen when repeating the test only 2 times. The test level is equal to 1.2. However, in our case, we needed to achieve a test strength of 0.25 , which is achieved by repeating the test at least 7 times. (see figures 4 and 5)

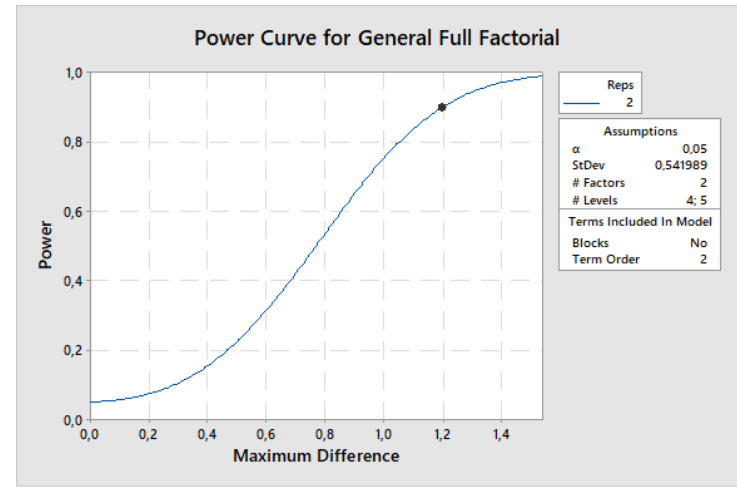

Fig. 4. Strength of test - Rvk

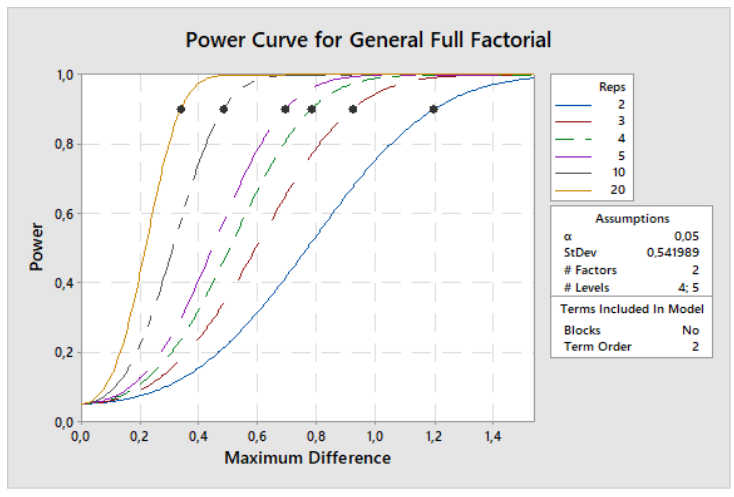

Fig. 5. Strength of test - Rvk

This evaluation method was performed for all the remaining parameters of the Abbott-Firestone curve. Only the required final test strengths are listed here and according to them the plan for further testing has been set.

The difference limit values were set to: 


\begin{tabular}{|c|c|}
\hline Parameters & Difference limit values \\
\hline Rk & 0.25 \\
\hline Rpk & 0.4 \\
\hline Rvk & 0.4 \\
\hline Rmr1 & 5 \\
\hline Rmr2 & 5 \\
\hline
\end{tabular}

Table. 3. Limited of strength of test

Based on the calculation of the strength of the tests shown in the graphs in figures 6 - 9 and Table 3 , it can be seen that according to the required limit values, at least 7 repetitions of measurements are required for the achieved results to be relevant.

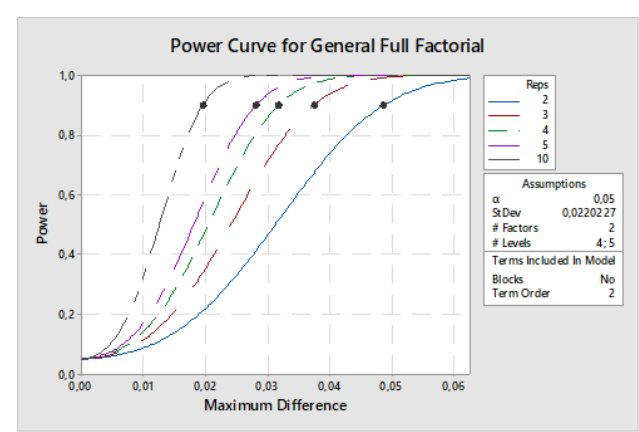

Fig. 6. Strength of test $-\mathrm{Rk}$

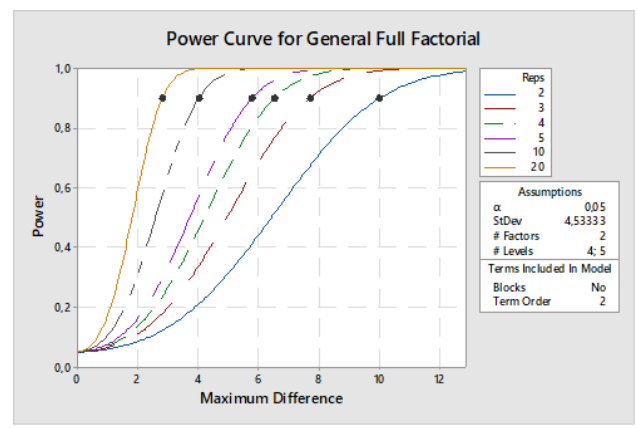

Fig. 8. Strength of test - Mr1

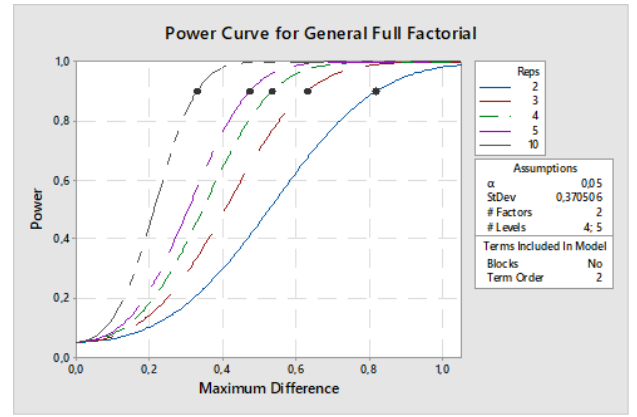

Fig. 7. Strength of test - Rpk

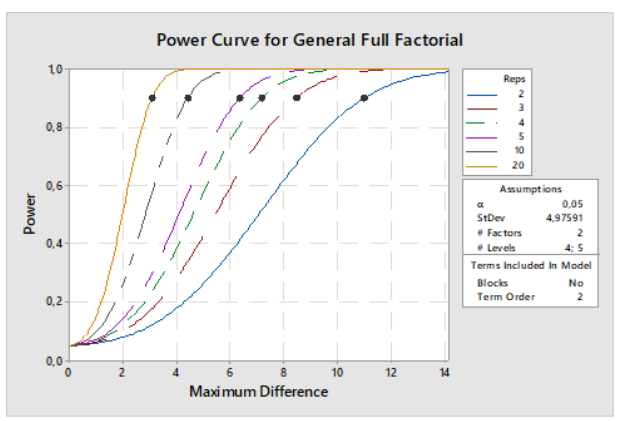

Fig. 9. Strength of test - Mr2

Based on these findings, we designed a new plan for an experiment with 7 repetitions. After this re-evaluation we first tested whether it is possible to join the first and second sets of data and thus increase the value of the test strength, i.e. the correctness of the created model. In all cases (Rk, Rvk, Rpk, Rmr1, Rmr2), the data in each block did not follow the normal distribution, so the non-parametric Mann-Whitney-Wilcoxon (MWW) test was used to compare the medians of both blocks to determine if they originated from the same distribution. After testing for the possibility of joining the blocks, it was proved that in all five cases it is possible to join the blocks and thus improve the accuracy of the subsequently created model.[10]

The procedure for the block joining test can be seen in the following tables. First, the null hypothesis was tested.

Null hypothesis:

Alternative hypothesis:

$\mathbf{N}$ number measured in group

Mean

StDev standard deviation

\section{Minimum}

Q1 $1^{\text {st }}$ quantile

Median

Q3 $3^{\text {rd }}$ quantile

Maximum
$\mathrm{H}_{0}: \eta_{1}-\eta_{2}=0$
Medians are the same in both blocks.
$H_{1}: \eta_{1}-\eta_{2} \neq 0$
Medians are different. 


\begin{tabular}{|c|c|c|c|c|c|c|c|}
\hline Block & Mean & StDev & Minimum & Q1 & Median & Q3 & Maximum \\
\hline 1 & 9.43 & 8.61 & 1.51 & 1.91 & 6.57 & 19.79 & 23.03 \\
\hline 2 & 9.539 & 8.655 & 1.55 & 1.952 & 6.61 & 19.61 & 25.52 \\
\hline
\end{tabular}

Table. 4. Result of Mann-Whitney-Wilcoxon test

As mentioned above, the task of the MWW test is to compare the medians of two or more independent blocks and decide whether they can be merged or not.

\begin{tabular}{|c|c|c|c|c|}
\hline & Normality & Med_1 & Med_2 & p-value \\
\hline Rk & NE & 6.57 & 6.61 & 0.420 \\
\hline
\end{tabular}

Table. 5. Mann-Whitney-Wilcoxon test results

Based on the p-value of the test, which came out at 0.420 , it can be said that the blocks do not differ from each other and can be seamlessly joined and considered as an experiment with 9 replications.

The second series of test evaluations was the same as the first; the effects of the standard, filter and their combination were investigated, but not using the Pareto plot, which can be used only in the case of normal data distribution. Based on the previous tests, we know that the data for parameters Rk, Rvk, Rpk, Rmr1 and Rmr2 are abnormal distributions. Therefore, only basic analysis was used for data analysis.

From the calculated basic characteristics as well as the plotted data in Figure 10, it can be seen that the type of standard will have a significant effect on the Rk parameter results.

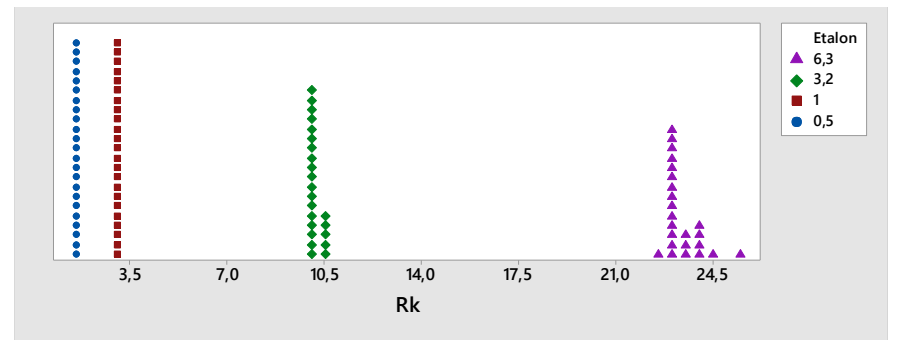

Fig. 10. Basic characteristics of standard

From the calculated characteristics and the plotted data in Figure 11, it is not obvious at first glance that the measured values would be affected by the filter selection.

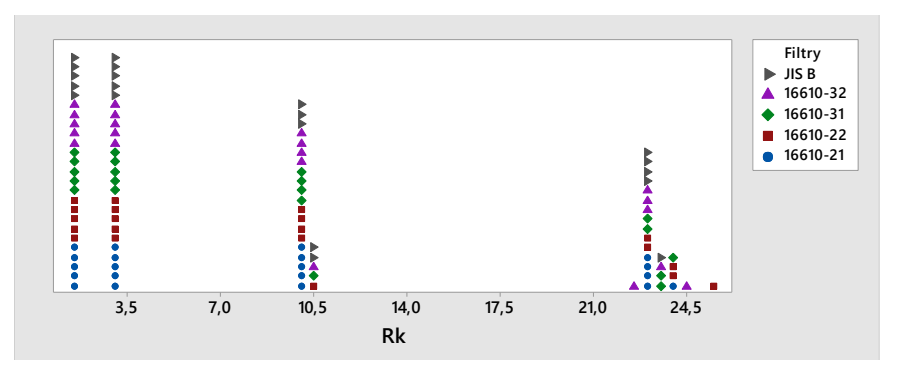

Fig. 11. Basic characteristics of filtr

The graphs suggest that the values of the Rk parameter are significantly influenced by the selected standard, but also by the double interaction between the standard*filter factors. The graphs (figures 12 and 13) showing averages by factor levels and their interaction, see below, do not support this conclusion. 


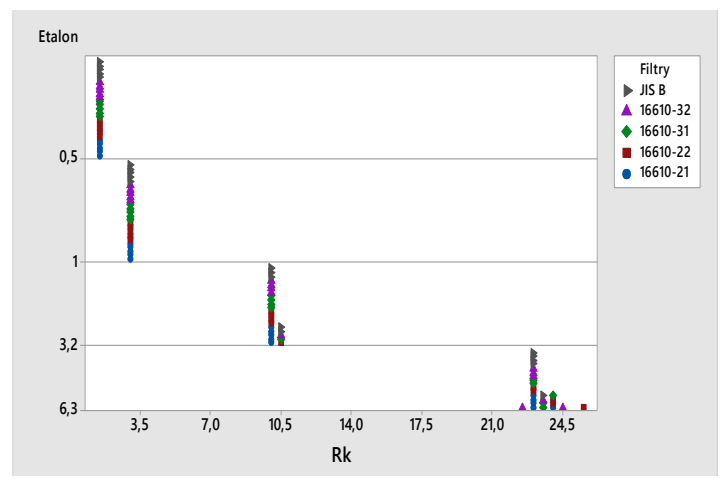

Fig. 12. double interaction between the standard*filtre

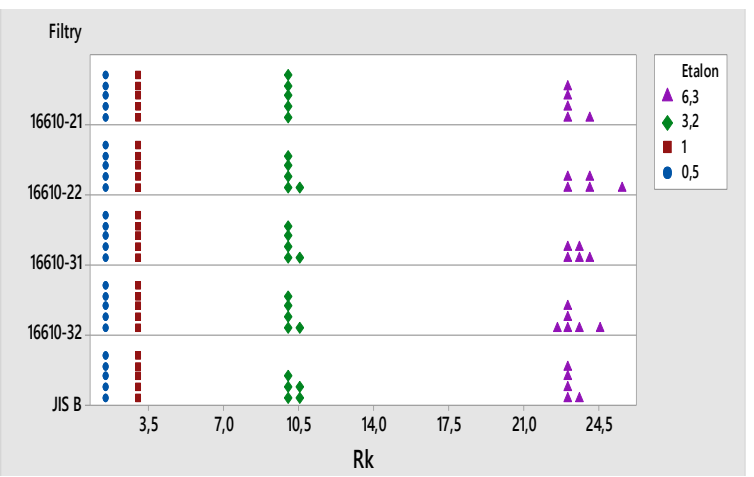

Fig. 13. double interaction between the standard*filtre

The influence of interactions is not visible at first glance.

Subsequently, based on the calculation using the ANOVA method, a model was constructed that predicts the reality with a probability of $99.98 \%$. Only the influence of the standard was included in the model, other effects were excluded based on their p-value.

\begin{tabular}{|c|c|c|c|c|c|}
\hline Source & DF & Adj SS & Adj MS & F-Value & P-Value \\
\hline Model & 19 & 32.9668 & 1.7351 & 42620.86 & 0.000 \\
\hline Linear & 7 & 32.9661 & 4.7094 & 115682.59 & 0.000 \\
\hline Standard & 3 & 32.9658 & 10.9886 & 269923.82 & 0.000 \\
\hline Filters & 4 & 0.0003 & 0.0001 & 1.67 & 0.161 \\
\hline 2-Way Interactions & 12 & 0.0007 & 0.0001 & 1.53 & 0.122 \\
\hline Standard*Filters & 12 & 0.0007 & 0.0001 & 1.53 & 0.122 \\
\hline Error & 140 & 0.0057 & 0.0000 & & \\
\hline Total & 159 & 32.9725 & & & \\
\hline
\end{tabular}

Table. 6. Table with result of ANOVA

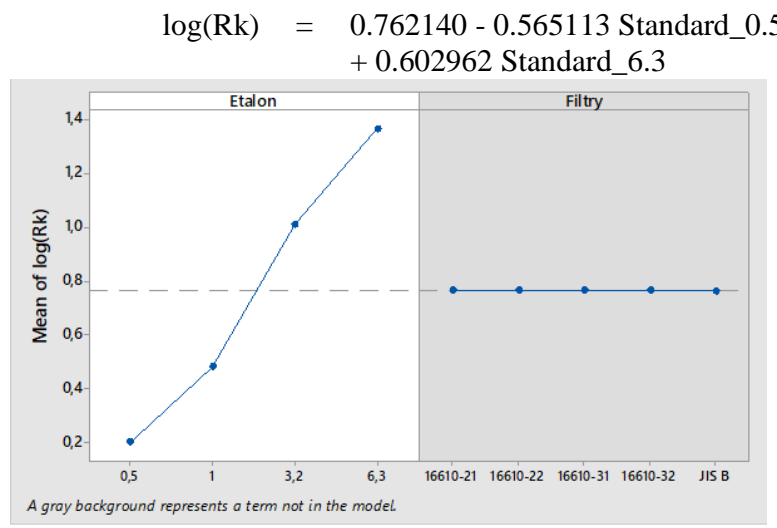

Fig. 14. Factor that are and are not in model

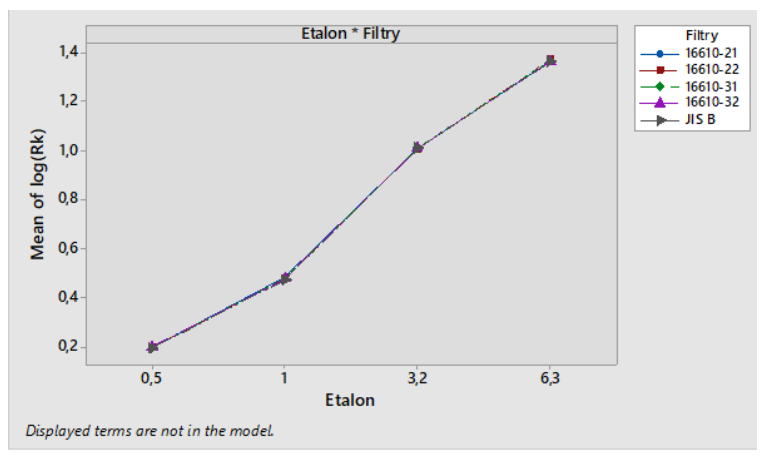

Fig. 15. Factor that are and are not in model

The mean effects of logarithms for each factor are shown in the resulting graphs (figures 14 and 15 - the white area indicates factors that are included in the model, they grey area indicates those not included in the model. The lowest values of Rk are for the standard 0.5, the highest values for the standard 6.3. As has been shown by the ANOVA results, the type of filter and the interaction between the standard and the filter have no influence on the measured values. 
The same principles for calculation and evaluation were applied to all the remaining parameters of the Abbot-Firestone curve. As for the Rk parameter, of the other parameters of the Abbot-Firestone curve only the standard was shown to have an influence. The influence of the software filter or the interaction of the standard and software filter was rejected.

Based on these findings, models for the remaining parameters of the Abbot-Firestone curve were constructed. For Rpk and Rvk they are of a linear nature, as can be seen in Table 7.

\begin{tabular}{|l|l|}
\hline Rpk & Rpk $=0.2484-0.1244$ Standard_0.5 - 0.0767 Standard_1 + 0.0718 Standard_3.2 + 0.1293 Standard_6.3 \\
\hline Rvk & Rvk $=0.2555-0.1305$ Standard_0.5 + 0.0265 Standard_1 -0.1784 Standard_3.2 +0.2823 Standard_6.3 \\
\hline
\end{tabular}

Table. 7. Table with models for Rpk a Rvk

For parameters Mr1 and Mr2 it was necessary to proceed with non-linear modelling using the Kruskal-Wallis test. The results can be seen in Table 8 .

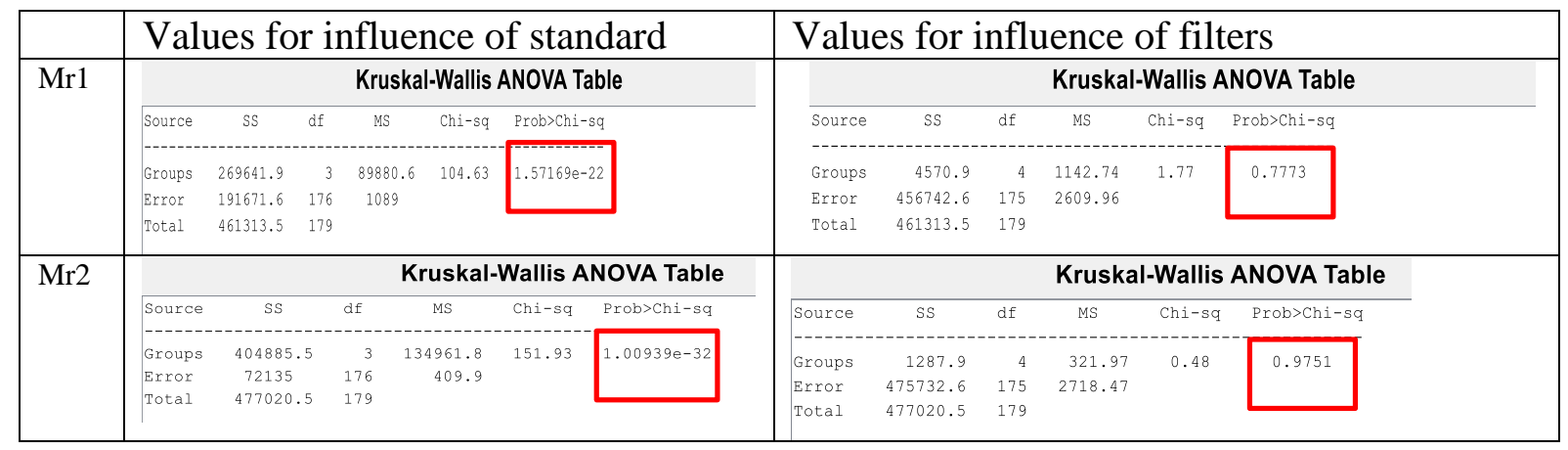

Table. 8. Table with models for Mr1 and Mr2

The information in the red boxes is very important to us. If the value in the field is lower than 0.05 , the parameter is significant. If the value exceeds 0.05 , the parameter is insignificant and can be neglected in further calculations.

\section{Conclusion}

Roughness is defined as very small irregularities from the ideal surface profile idealized as an exactly flat and smooth, glossy surface. Roughness is created, for example, by the action of a cutting tool or grinding wheel. The roughness of the surface does not take into account accidental damage (bulges, burrs, bumps, ridges, bumps) and original material defects such as pores and cracks. The number of surface changes is also affected by roughing or finishing operations.

The correct way of monitoring and evaluating the microgeometry of the surface layer is a fundamental factor in ensuring the durability, strength, reliability and efficiency of machine parts. Due to functional surface requirements, many surface roughness parameters have been introduced to provide a trustworthy description, although most possible parameters in surface roughness evaluation are neglected in current technical practice. In the development of a more accurate description, the height characteristics $(\mathrm{Ra}, \mathrm{Rz}, \ldots)$ were supplemented with shape characteristics $(\mathrm{Rmr}, \mathrm{Rdc}, \ldots)$ and subsequently with shape parameters that determine the bearing load share $(\mathrm{Rk}, \mathrm{Rvk}, \ldots)$. The paper is further focused on shape parameters determining the bearing load share, i.e. parameters on the Abbott-Firestone curve. These are described in ISO 13565-2: 1998, which was based on the German standard DIN 4777: 19990, which was the first to introduce the form function parameters using the graphic construction of the bearing load curve.

The Abbott-Firster curve is used to evaluate the parameters Rk, Rpk, Rvk, Mr1, Mr2, which are obtained from the filtered surface and are usually evaluated based on a graphical representation.

The tests tested the influence of the used software filter on the surface roughness measurement on the parameters of the Abbot-Firestone curve using different values of surface roughness. The change in surface roughness value was made using binding surface roughness standards with nominal RA0.5 values; RA1; RA3,2; RA6,3 all standards with periodic surface structure.

A number of statistical analyses were used for the evaluation of the test, which in all cases showed the influence of the choice of the standard. In no cases did the effect of the used software filter or the interaction between the standard and the software filter appear. The results were always proven by a statistical test at a significance level of 5\%, which was either the ANOVA method and subsequent testing of the significance of the coefficients in the regression model, or the non-parametric Kruskal-Wallis test if ANOVA assumptions were violated.

Based on the results we achieved, it is possible to recommend an evaluation using the Abbott-Firestone curve as very beneficial for technical practice. Especially in areas where it is necessary to compare the achieved survey results in multiple metrology laboratories. Because, as demonstrated by the test using different software filters, the results were not biased or affected in any way. 


\section{Acknowledgments}

This paper was created within the project GA UWB in Pilsen: SGS-2019-008 "Research and development for innovation in the field of manufacturing processes - Technology of metal cutting III".

\section{References}

[1] ISO/TS 16610-1 Technical specification ISO/TS 16610. Geometrical product specifications (GPS) - Filtration, 2015.

[2] EN ISO 16610-20. Geometrical product specifications (GPS) - Filtration - Part 20: Linear profile filters: Basic concepts. Brussels: ÚNMZ, 2015.

[3] ČSN ISO/TS 16610-21 Geometrical product specifications (GPS) - Filtration - Part 21: Linear profile filters: Gauss filters. Brussels: ÚNMZ, May 2012

[4] EN ISO 16610-40. Geometrical product specification (GPS) - Filtration - Part 40: Morphological profile filter: Basic concepts, 2016

[5] EN ISO 4287. Geometrical product specification (GPS) - Surface structure: Profile method - Terms, definitions and surface texture parameters - Part 1; Brussels: CEN, 1999.

[6] http://www.hommel-etamic.cz/cz/technicke-informace/drsnost-povrchu-dle-din-en-iso/ [online]. [2016-08-27]

[7] http://www.techno-mat.cz/data/katedry/kom/KOM_MM_PR_10_CZE_Karasek_Geometricke_vlastnosti_povrchu [online]. [cit. 2018-08-01].

[8] https://www.olympus-ims.com/en/knowledge/metrology/roughness/[online]. [cit. 2018-09-01].

[9] https://www.hommel-etamic.cz/files/2009-13_en_roughness_poster.pdf[online]. [cit. 2017-09-01].

[10] Melichar M., Kutlwašer J.,Kubátová D.: (2016). Effect of Sweat Aggressiveness on Parameters of Surface Integrity., 0536. DOI: 10.2507/26th.daaam.proceedings.073. Available at: http://www.daaam.info/Downloads/Pdfs/procee dings/proceedings_2015/073.pdf

[11] E.S. Gadelmawla, M.M. Koura, T.M.A. Maksoud, I.M. Elewa, H.H. Soliman,: (2002) Roughness parameters, In Journal of Materials Processing Technology, Volume 123, Issue 1, , Pages 133-145, ISSN 0924-0136, https://doi.org/10.1016/S0924-0136(02)00060-2. z:http://www.sciencedirect.com/science/article/pii/S0924013602000602

[12] E.Clayton Teague, Fredric E. Scire, Saul M. Baker, Stephen W. Jensen, (1982)Three-dimensional stylus profilometry, In Wear, Volume 83, Issue 1, , Pages 1-12, ISSN 0043-1648, https://doi.org/10.1016/00431648(82)90335-0.Available at:http://www.sciencedirect.com/science/article/pii/0043164882903350

[13] M. Shah Mohammadi, M. Ghani, M. Komeili, B. Crawford, A.S. Milani, (2017) The effect of manufacturing parameters on the surface roughness of glass fibre reinforced polymer moulds, In Composites Part B: Engineering, Volume 125, Pages 39-48, ISSN 1359-8368, https://doi.org/10.1016/j.compositesb.2017.05.028. Available at: http://www.sciencedirect.com/science/article/pii/S1359836816317887)

[14] D. Kubátová and M. Melichar: (2018) "Post Processing of Roughness Raw Data", Solid State Phenomena, Vol. 278, pp. 15-22, 2018

[15] Kubatova, D[ana]; Melichar, M[artin] \& Kutlwaser, J[an] (2018). Methodology for Selecting Software Filters, Proceedings of the 29th DAAAM International Symposium, pp.1266-1272, B. Katalinic (Ed.), Published by DAAAM International, ISBN 978-3-902734-20-4, ISSN 1726-9679, Vienna, Austria DOI: 10.2507/29th.daaam.proceedings. 182

[16] Zaujec, R[udolf]; Vopat, T[omas]; Simna, V[ladimir] \& Jurina, F[rantisek] (2018). Coating of Cutting Tool and CAM Milling Strategy Influence on the Tool Wear and Surface Roughness, Proceedings of the 29th DAAAM International Symposium, pp.1273-1278, B. Katalinic (Ed.), Published by DAAAM International, ISBN 978-3902734-20-4, ISSN 1726-9679, Vienna, Austria DOI: 10.2507/29th.daaam.proceedings.183 